\title{
PHENOMENAL CONCEPTS AND PHYSICAL FACTS: A DIALOGUE WITH MARY
}

\author{
TUFAN KIYMAZ, Bilkent University, Department of Philosophy, Bilkent, Ankara, Turkey
}

KIYMAZ, T.: Phenomenal Concepts and Physical Facts: A Dialogue with Mary FILOZOFIA, 74, 2019, No 10, pp. $797-807$

This is a dialogue between an opponent of the phenomenal concept strategy and Mary from Frank Jackson's knowledge argument. In this dialogue, Mary, who has complete physical knowledge about what it is like to see red, but has never seen red, is a physicalist and she defends the phenomenal concept strategy against her interlocutor's objections. In the end, none of them is able to convince the other, but their conversation, through considerations of different versions of the knowledge argument and different applications of the phenomenal concept strategy, reveals the most basic disagreement, or clash of intuitions, they have. The implied conclusion of the dialogue is that the disagreement on the success of phenomenal concept strategy as a physicalist response to the knowledge argument cannot be resolved unless this particular clash of intuitions is resolved.

Keywords: Phenomenal concepts - Knowledge argument - Physicalism - Phenomenal knowledge

S: Hello Mary. ${ }^{1}$ If you are ready, we can start today's session. How are you feeling today?

M: I'm great! I am just told that later this evening, at $\mathrm{t}_{1}$, I'll be released from my blackand-white room and I'll see a red tomato for the first time. I'll experience what it is like to see red. I'm so excited!

S: That's great news, but I don't think I understand why you are excited. You have complete physical knowledge of human visual experiences and, as far as I know,

\footnotetext{
${ }^{1}$ Mary is the protagonist in Frank Jackson's $(1982,1986)$ knowledge argument against physicalism. She is a super scientist who has complete scientific knowledge of all physical (including physically realized functional) facts about human visual experiences. However, she lives in a black-and-white room and she has never experienced what it is like to see a color. One day she leaves the room, sees a red tomato, and exclaims: "So, this is what it is like to see red!" According to Jackson, since Mary learns a new truth about human color experiences, her complete knowledge of physical facts was not complete knowledge of human color experiences, which means that there are some nonphysical facts about those experiences.
} 
you are a physicalist. ${ }^{2}$ So, don't you think you already know what phenomenal property your visual experience will have?

M: I know exactly what phenomenal property my experience will have. It is R, which is a complex physical property. ${ }^{3}$

S: Okay, if physicalism is true, $\mathrm{R}$ is what it is like to see red. You deduced this from your complete physical knowledge about human visual experiences that you have learned from your books. But, you will be surprised upon having an experience that has the property R, won't you? And that's why you are excited now.

M: Yes, I'll be surprised because I'll apprehend R under a phenomenal concept that I don't possess now. ${ }^{4}$

S: So, do you know which phenomenal concept you will acquire?

M: Yes, I'll acquire the phenomenal concept that utilizes R to denote R. ${ }^{5}$ What will surprise me is using that phenomenal concept for the first time.

S: I don't think this is a plausible explanation of your future surprise. May I try something? I happen to have two crayons in my pocket, one is red and the other is green. I'll show them to you without telling which one is which. So, according to your theory, you will acquire two phenomenal concepts, one denotes $\mathrm{R}$, the

\footnotetext{
${ }^{2}$ Mary is not a physicalist in Jackson's $(1982,1986)$ arguments. I am reimagining Mary as a physicalist.

3 Throughout the paper I will use the term "physical property" in a wide sense that includes properties that are mentioned in (completed) physics, chemistry, biology, etc. and causal/functional properties whose instantiations are metaphysically determined by those properties mentioned in physics, chemistry, biology, etc. I will, however, sometimes use the term "physical/functional" instead of "physical" to emphasize that I am not necessarily talking about properties mentioned in physics proper. An important implication of the conception of physicality that I am using in this paper is that all physical facts can be objectively expressed and discursively learned. This point is essential for Jackson's knowledge argument.

${ }^{4}$ Mary employs the phenomenal concept strategy (the name is dubbed by Stoljar (2005). Some prominent defenders of this response to the knowledge argument are Horgan (1984), Loar (1997), Perry (2001), Byrne (2002), Papineau (2002, 2007), Balog (2012) among many others. According to the phenomenal concept strategy, phenomenal knowledge is knowledge that involves phenomenal concepts, and (excluding miracles) phenomenal concepts can only be acquired through phenomenal experience. What a phenomenal concept picks out, according to this view, is a physical property. So, the claim is that what Mary learns upon seeing a red tomato is not a new truth, but a new way of apprehending a truth that she already knows in physical terms.

${ }^{5}$ This is a common view among phenomenal concept strategists. For example, according to Loar (1997), the reference of the phenomenal concept is utilized in its mode of presentation. Similarly, Papineau, both in his earlier quotational-indexical model (2002) and his more recent perceptual concept model of phenomenal concepts (2007) maintains that phenomenal concepts use phenomenal experiences in order to mention them. Balog (2012) argues that, in canonical, first-person, present tense applications of phenomenal concepts, the token concept is partly constituted by the token experience that it denotes and other applications of phenomenal concepts are dependent on the canonical application.
} 
phenomenal property of red-seeing experience, and the other denotes $G$, the phenomenal property of green-seeing experience. You will be able to use those phenomenal concepts and, say, be able to ask whether what it is like to see red is such-and-such or not, or form the belief that sky does not look such-and-such. Are you ready?

M: Well, that will certainly diminish the surprise at $\mathrm{t}_{1}$, but okay, I'm ready.

S: Here they are. Now you have two new phenomenal concepts, right?

M: Yes.

S: Let's call the phenomenal concept you acquired by seeing this crayon " $A$ " and the other one " $B$ *". They denote the phenomenal qualities A and B, each of which is identical to either R or G. ${ }^{6}$

M: Okay.

$\mathrm{S}:$ Here is my question. Will you employ $A^{*}$ or $B^{*}$ at $\mathrm{t}_{1}$ when you see a red tomato?

M: I'll employ the one that is coreferential with the physical concept $R$.

S: Okay, but which one is that? $A^{*}$ or $B^{*}$ ? Or, let me ask you a yes-or-no question. Will you employ $A^{*}$ at $\mathrm{t}_{1}$ ?

M: If it corefers with $R$, yes, I will. If it doesn't corefer with $R$, then I won't.

S: Does $A^{*}$ corefer with $R$ ?

M: I don’t know.

\footnotetext{
${ }^{6}$ I write a term (or schematic letter for a term) that expresses a concept in italics when I talk about the concept. Otherwise, I use the concept rather than refer to it. I use "*” to signify phenomenal concepts. I'll also use $A$ and $B$ as the physical concepts that are, if physicalism is true, coreferential with $A^{*}$ and $B^{*}$, respectively.

${ }^{7}$ This question is inspired by Stoljar's (2005) Experienced Mary argument. Mary, in Stoljar's example, escapes from the room, sees colors, and thereby acquires phenomenal concepts about color vision. She also learns propositional knowledge that can only be comprehended through employment of those phenomenal concepts, such as " $\mathrm{R}^{*}$ is what it is like to see red" and "people normally see $G^{*}$ when they look at the grass." However, Mary is recaptured and during her capture she develops partial amnesia. She forgets all the propositional knowledge she has acquired after her escape, but she still possesses the phenomenal concepts. So, now, Experienced Mary has the phenomenal concepts but does not know, and cannot deduce from her physical knowledge, whether $\mathrm{R}^{*}$ is what it is like to see red, or green, or another color. Even if Mary's lack of some phenomenal concepts could explain her inability to deduce phenomenal knowledge from physical knowledge, Experienced Mary's ignorance cannot be explained this way, since she does possess the phenomenal concepts. Stoljar's argument, as he points out, is a development of Nida-Rümelin's (2004) Marianna example. A similar case is used in a response to type-A materialism by Chalmers $(2004,284$ -285). Also, see Warner $(1986)$ and Tye $(2009,134)$ for similar scenarios.
} 
S: Thanks for the straightforward answer. So, you don't know now, but at $\mathrm{t}_{1}$ you will learn whether $A^{*}$ corefers with $R$ or not, right? So, doesn't this mean that you will learn a new truth at $\mathrm{t}_{1}$ that you don't know now?

M: No, I won't learn a new truth. Let me explain. It is like the coreferential concepts The Morning Star and The Evening Star, but suppose neither concept utilizes a contingent property of its referent in the mode of presentation. $R$ refers to $\mathrm{R}$ under its physical description, and $A^{*}$ or $B^{*}$ refers to $\mathrm{R}$ by utilizing $\mathrm{R}$ itself. But, there is no property involved in the mode of presentation of a phenomenal concept, whether it is $A^{*}$ or $B^{*}$, that I don't already know under its physical description. Okay, let me put this another way. At $\mathrm{t}_{1}$, either the fact that I deploy $A^{*}$ or the fact that I deploy $B^{*}$ will hold. One of those facts is identical to the fact that I phenomenally conceptualize R. Whichever is identical to that fact, that will hold at $\mathrm{t}_{1}$. And I know which phenomenal concept I'll deploy at $t_{1}$; it is the one that utilizes $\mathrm{R}$ in its mode of presentation. There is no further fact about that phenomenal concept that I don't already know. ${ }^{8}$

S: Okay. I think I understand what you are saying, but I don't agree. Would you be willing to help me with a quick experiment? We know that at $\mathrm{t}_{1}$ you will deploy either $A^{*}$ or $B^{*}$, both of which you now possess, correct?

M: Correct.

S: Here is the instruction for the experiment: At $t_{1}$, when you see a red tomato, raise your left hand if you represent $\mathrm{R}$ under $A^{*}$ and raise your right hand if you represent $\mathrm{R}$ under $B^{*}$. Can you follow this instruction?

M: Yes, sure.

S: So, at $t_{1}$, either you will raise your left hand or you will raise your right hand. Which of these physical facts will hold at $\mathrm{t}_{1}$, given that you'll follow the instruction?

\section{M: I don't know. ${ }^{9}$}

\footnotetext{
${ }^{8}$ Here, Mary claims that she knows which phenomenal concept she will deploy since she has complete knowledge of the phenomenal concept under its physical description, even if she does not know which phenomenal concept corresponds to that physical description under its phenomenal conceptualization. This response is inspired by Balog's (2012) response to Chalmers's (2007) Master Argument against the phenomenal concept strategy, where she distinguishes between phenomenal and physical conceptualizations of phenomenal concepts.

${ }^{9}$ A priori physicalists (or type-A materialists) would not agree that Mary would say "I don't know" here. Consider, for example, Daniel Dennett's "blue banana" objection to Jackson (Dennett 1991, $399-400)$. However, any supporter of the phenomenal concept strategy, which Mary endorses in this dialogue, would agree that Mary would give this answer at this point.
} 
S: So, you don't know which of these physical facts will hold at $t_{1}$, because the instruction is about your phenomenal experience and you don't know what you will experience. That you know that your experience will have the property $\mathrm{R}$ is irrelevant now. You don't know something else about your future experience, namely what having an experience that has $\mathrm{R}$ will be like for you, and, based on this, you don't know which hand you will raise, which is, again, a physical event.

M: But you are ignoring the fact that the instruction you gave me involves phenomenal concepts. And I do admit that I don't know whether I will deploy $A^{*}$ or $B^{*}$ under their phenomenal conceptualizations. But there is no fact about my future experience that I don't know under a physical description.

S: But you just said that you don't know whether you will raise your left hand or right hand.

M: If you gave me the instruction without using the phenomenal concepts, then I would know which hand I'll raise.

S: But that wouldn't be the same instruction. That would be something like this: "Raise your left hand if you represent $\mathrm{R}$ under the phenomenal concept that utilizes $\mathrm{R}$ in its mode of presentation and raise your right hand if you represent $\mathrm{R}$ under a phenomenal concept that does not utilize $\mathrm{R}$ in its mode of presentation." If this were the instruction, then of course you would know that you would raise your left hand. But this is not the experiment I am trying to conduct. I want to focus on your visual phenomenal experiences of these two crayons because I want to show you that not knowing which of these two phenomenal qualities is what it is like to see red, under their phenomenal conceptualizations, amounts to not knowing a substantive fact. Given this, I don't think there is anything illicit in formulating the instruction the way I did.

M: Let's see. I completely grasp the instruction, I also completely grasp the physi$\mathrm{cal} /$ functional description of my future experience at $\mathrm{t}_{1}$, but $\mathrm{I}$ fail to predict which hand I'll raise given that I'll follow the instruction, which implies a substantial lack of knowledge about some fact on my part. This is your argument, right? And, as you just said, if the instruction only consisted of physical/functional terms, I would have no difficulty predicting which hand I'll raise. All this shows, I think, is that your instruction cannot be expressed in purely physical/functional terms. ${ }^{10}$ But, this is perfectly understandable, because phenomenal concepts are not a priori

${ }^{10}$ Strictly speaking, logical or mathematical terms would also be involved, but I omit this detail. 
reducible to physical/functional concepts. I still cannot see how your experiment is supposed to pose a problem for my physicalist account.

S: This is not about a priori reducibility. A priori or not, what is expressed in my instruction cannot be captured by any instruction in physical/functional terms. But, isn't it your claim that even if one cannot a priori see it, any fact that can be expressed with phenomenal concepts can also be expressed in physical/functional terms?

M: Yes, exactly! But, an instruction is not a fact. All I claim is that every FACT that is apprehensible through phenomenal concepts can also be apprehended in physi$\mathrm{cal} /$ functional terms. What if this is not true for instructions? What if there are irreducibly phenomenal instructions that cannot be expressed in physical/functional terms? I can't see how this would mean that there are nonphysical facts.

S: Why would this instruction be irreducibly phenomenal, in the sense that it cannot be expressed in physical / functional terms, if every concept in it corefers with a physi$\mathrm{cal} /$ functional concept?

M: Suppose pain* refers to c-fiber activation. That I am in pain* is the same fact as that I am in the c-fiber activation state, but from one's knowing that she is in pain* it does not follow that one knows that she is in c-fiber activation state, in the finegrained sense. Phenomenal concepts are cognitively isolated from physical/functional concepts. Even though I know every physical fact about human color vision, I cannot deduce from my physical/functional knowledge the identity statement involving $A^{*}$ and a physical/functional concept. My point is this. There are no irreducibly phenomenal facts, but there is irreducibly phenomenal knowledge, which involves irreducibly phenomenal concepts. These concepts are irreducibly phenomenal not in the sense that they denote something that cannot also be picked out by a physical/functional concept, but in the sense that their mode of presentation involves exemplifying a phenomenal property and one cannot possess that concept unless, miracles excluded, one has, or has a memory of, the experience that the concept denotes. And, your instruction involves such phenomenal concepts that are cognitively isolated from other concepts. So, it is perfectly understandable why I fail to predict which hand I will raise.

S: I don't understand how this is supposed to solve the problem. You know every physical/functional fact about the red-seeing experience, but obviously you don't know how it feels to have that experience, since you cannot predict which hand you will raise, given that you follow my instruction. So, red-seeing experience has a property, a way in which it differs from other experiences, that cannot 
be described in physical/functional terms. This definitely sounds metaphysically significant. We are talking about a property that cannot be reduced to physical properties. Okay, let me put it this way. A few minutes ago, at to, I showed you two crayons. Before $t_{0}$, you knew all the physical/functional differences between the red-seeing experience and the green-seeing experience, under their physical/functional descriptions. Then, seeing the crayons, you had two new color experiences and, at $t_{1}$, you will learn which of those experiences corresponds to the red-seeing neural state under its phenomenal conceptualization, to use your terminology. So, your $t_{1}$-list of the differences between the red-seeing experience and the green-seeing experience has one more item than your to-list. That new item cannot be expressed as any of the items in your $t_{0}$-list. If it could be so expressed, then my instruction could be expressed in physical/functional terms, which is not the case. As you admitted before, if the instruction consisted of only non-phenomenal concepts, then you would easily predict which hand you'd raise at $t_{1}$. Which would be a trivial task, actually. But, even if you have complete physical knowledge about the experience you'll have at $t_{1}$, you can't predict which hand you'll raise if the instruction involves phenomenal concepts. The extra item in the $t_{1}$-list involves exactly those phenomenal concepts that are in my instruction. Since your to-list was the list of all physical/functional differences between those two experiences, the extra item in the $t_{1}$-list, which is about the phenomenological difference, must be a difference that is not physical/functional.

M: But if those phenomenal concepts involved in the extra item refer to physical properties and don't utilize any nonphysical property in their mode of presentation, then the extra item would not be problematic for the physicalist.

S: I agree. But if this were the case, then that extra item would be equivalent to some item or combination of items in the $t_{0}$-list, since $t_{0}$-list is supposed to be a complete list of all the differences between those two experiences. But, it is not equivalent to anything in your $\mathrm{t}_{0}$-list. So, your account of phenomenal concepts must be false.

M: Okay, now I can see more clearly where you are mistaken. The new item in the $t_{1}$-list is not epistemically or conceptually reducible to anything in the $t_{0^{-}}$ -list, I agree. This is because the new item consists in the USE of a property, but the $t_{0}$-list only MENTIONS the properties. ${ }^{11}$ Suppose you have a list of all the letters in the American Sign Language manual alphabet. Your list consists of descriptions of 26 hand signs each corresponding to a letter in the English

\footnotetext{
${ }^{11}$ According to Papineau $(2002,2007)$, confusion between the use and mention of a phenomenal property, which he calls the "antipathetic fallacy" (Papineau 1993, 1995), explains the intuition of distinctness between the phenomenal and the physical (see also Tye 1999, 712 - 713, cf. Sundström 2008).
} 
alphabet. Your list is complete, all the information about the letters in the manual alphabet is there. But, then, imagine I raise my hand, make a victory sign and say "your list is incomplete; your list doesn't include this sign." You will of course say that what I am doing is letter V and it is indeed mentioned in your list. But, imagine I insist and say that my particular hand sign is a letter in the manual alphabet but this, the performed hand sign itself, is not in your list, therefore your list is incomplete. You can see my point, right? Obviously, I am making a category mistake here. When I make the sign, my hand actually realizes one of the descriptions in your list, but the hand sign, as actually being performed, is not something that can be in your list, which consists in written descriptions. This doesn't mean that your list leaves out a letter from the manual alphabet. Likewise, my to-list doesn't leave out any property that red-seeing experience has but green-seeing experience doesn't. The so-called extra item in the $t_{1}$-list is not an extra property, it is an instance of deployment of a property in a phenomenal concept. The $t_{0}$-list mentions all of the relevant properties, and the extra item in the $t_{1}$-list uses one of the properties mentioned in the $t_{0}$-list, just like I am now performing one of the letters mentioned in the list of the letters of the ASL manual alphabet.

S: I think I understand your strategy and, I must admit, it is rather clever. But, I still disagree. At this point, it seems to me, I can only express my objection as a Moorean shift. I understand how your theory of phenomenal concepts is supposed to block the antiphysicalist argument from the irreducibility of phenomenal knowledge. Now, the question is this; which one is more obviously true, your theory of phenomenal concepts, or that when you see red for the first time, you learn a new difference between the red-seeing experience and the green-seeing experience that you didn't know before? It seems to me denying that you learn a new way in which red-seeing experience differs from green-seeing experience when you see red for the first time amounts to denying the reality of phenomenological difference between two experiences. I introspectively know that phenomenological difference is real. This is much more obviously true than your theory about phenomenal concepts. Let me make the Moorean shift clearer. Do you think the following argument is sound?

M: I'm listening.

S: Let's call your theory of phenomenal concepts "PCT." (1) If PCT is true, then, for all we know, $\mathrm{t}_{1}$-list does not have a new item that is not also in the $\mathrm{t}_{0}$-list. (2) PCT is true. (3) Therefore, for all we know, $t_{1}$-list does not have a new item that is not also in the $t_{0}$-list. Is this argument sound? 
M: Yes, I think so. And, if physicalism is true, it is actually the case that $\mathrm{t}_{1}$-list does not have a new item that is not also in the to-list.

S: Okay. And, here is my argument. The first premise is identical to the first premise of the previous argument. (1) If PCT is true, then, for all we know, $\mathrm{t}_{1}$-list does not have a new item that is not also in the $t_{0}$-list. (2) I know that $t_{1}$-list has a new item that is not also in the $t_{0}$-list. (3) Therefore, PCT is false. There are some tacit premises in this argument, but I think you would agree that the conclusion follows from the premises, right?

M: Yes, I agree.

S: Now, the second premise of my argument is, to me, much more obviously true than the second premise of the previous argument. I think it is obvious that you learn a new way in which red-seeing experience differs from green-seeing experience when you see red for the first time. You learn how red-seeing experience differs from green-seeing experience phenomenologically. Phenomenological difference between two experiences is real difference. This, again, for me, is much more obviously true than your theory of phenomenal concepts. But, at least, now we can identify our most basic disagreement. It seems to me, you believe that the phenomenology of having an experience can be reduced to the way in which one conceptualizes that experience. I disagree. I believe what is experienced from the first person perspective is real, but you think it isn't. I believe that subjective experiences are real, you believe that they are illusory.

M: No, of course not! I do think that the subjective experiences are real. They are not illusory. They are real; real and physical.

S: Here is what I mean. If you gave me a list of all the physical differences between a chair and a table, I would not feel that something is missing in your list. But, when you give me all the physical/functional differences between two conscious brain states, and you do not include in your list anything about how it feels to be in one mental state and not the other, I think you are obviously missing something. Those experiences differ in a way that is epistemically accessible only to the subjects of those experiences, which cannot be captured by descriptions of neuronal activities and functional/causal relations between brain parts. But, your account denies this. I think you assume that if a difference between two mental states cannot be objectively described, then it is not real. I disagree. I think phenomenal qualities are real, I think they are subjective, and I think subjectivity and objectivity are mutually exclusive. 
M: Okay, now we have made some progress. The mutual exclusivity of the subjective and the objective is exactly what I deny. Subjective experience is nothing but a brain process, which is objectively describable. The difference between the subjective and the objective is just a difference in conceptualization, not in what is being conceptualized. I believe that no actually instantiated property is ONLY accessible from the first person perspective. Some properties, namely conscious mental properties, are accessible from the first person perspective, as well as the third person perspective.

S: Okay, then, would you agree that this is our most basic disagreement: I believe that there is exclusive subjectivity, but you don't. That is, I believe that something metaphysically significant is not captured when you conceptualize a subjective experience objectively, but you don't.

M: Yes, I agree. And, with my ASL manual alphabet example, I tried to show you that you have this intuition of exclusive subjectivity because of a use-mention fallacy. But, you say that the truth of your intuition is more obvious to you then the truth of my explanation based on PCT. So, at this point, I have no idea how I can convince you.

S: Yes, my intuition is that what is accessible from the first person perspective, the what-it-is-likeness of the experience, is accessible only from the first person perspective. Given that the physical is, at least in principle, objectively accessible, then conscious mental states are not physical. I say, let's both take our time and contemplate about this further. Why do I think that the first person perspective is exclusive, and why do you disagree? This might call for some experimental philosophy, actually. Okay then, this is the end of our session. I think this was illuminating even though we couldn't resolve our disagreement.

M: Yes, see you next time! I'll be at the vegetable garden right outside my room.

\section{Bibliography}

BALOG, K. (2012): In Defense of the Phenomenal Concept Strategy. Philosophy and Phenomenological Research 84 (1), $1-23$.

BYRNE, A. (2002): Something about Mary, Grazer Philosophische Studien 62 (Essays in Honour of the Philosophy of Terence Horgan, J. Brandl \& O. Markic), $123-140$.

CHALMERS, DAVID J. (2004): Phenomenal concepts and the knowledge argument. In: Ludlow, P. - Stoljar, D. \& Nagasawa, Y. (eds.): There's Something About Mary: Essays on Phenomenal Consciousness and Frank Jackson's Knowledge Argument. Massachusetts: MIT Press.

CHALMERS, D. J. (2008): Phenomenal Concepts and the Explanatory Gap. In: Alter, T. - Walter, S. (eds.): Phenomenal Concepts and Phenomenal Knowledge: New Essays on Consciousness and Physicalism. Oxford: Oxford University Press.

DENNETT, D. (1991): Consciousness Explained. London: Little \& Brown; reprinted, London: Penguin, 1993

HORGAN, T. (1984): Jackson on Physical Information and Qualia. Philosophical Quarterly, 34, 147- 152. 
JACKSON, F. (1982): Epiphenomenal Qualia. The Philosophical Quarterly 32 (127), 127 - 136. DOI: https://doi.org/10.2307/2960075.

JACKSON, F. (1986): What Mary Didn't Know. The Journal of Philosophy 83 (5): 291 - 295. DOI: https://dx.doi.org/jphil198683566

LOAR, B. (1997): Phenomenal states (second version). In: Block, N. - Flanagan, O. \& Güzeldere, G. (eds). In: Flanagan, O. J. - Block, N \& Güzeldere, G. (eds.), The Nature of Consciousness. Massachusetts: MIT Press.

NIDA-RÜMELIN, M. (2004): What Mary Couldn't Know: Belief About Phenomenal States. In: Peter Ludlow, Daniel Stoljar \& Yujin Nagasawa (eds.), There's Something About Mary: Essays on Phenomenal Consciousness and Frank Jackson's Knowledge Argument. MIT Press.

PAPINEAU, D. (1993): Physicalism, consciousness and the antipathetic fallacy. Australasian Journal of Philosophy, 71 (2), 169 - 183.

PAPINEAU, D. (1995): The antipathetic fallacy and the boundaries of consciousness. In: Metzinger, T. (ed.): Conscious Experience. Ferdinand Schoningh.

PAPINEAU, D. (2002): Thinking about Consciousness. Oxford: Clarendon Press.

PAPINEAU, D. (2007): Phenomenal and perceptual concepts. In: Torin, A. - Walter, S. (eds.): Phenomenal Concepts and Phenomenal Knowledge. Oxford: Oxford University Press, $111-144$.

PERRY, J. (2001): Knowledge, Possibility and Consciousness. The 1999 Jean Nicod Lectures. Cambridge (MA): MIT Press.

STOLJAR, D. (2005): Physicalism and Phenomenal Concepts. Mind \& Language 20 (5), 469 - 494. DOI: https://doi.org/10.1111/j.0268-1064.2005.00296.x

SUNDSTRÖM, P. (2008): Is the mystery an illusion? Papineau on the problem of consciousness. Synthese, 163 (2), 133 - 143. DOI:10.1007/s11229-007-9193-6

TYE, M. (1999): Phenomenal consciousness: the explanatory gap as a cognitive illusion. Mind, 108 (432), $705-725$.

TYE, M. (2009): Consciousness Revisited: Materialism Without Phenomenal Concepts. Massachusetts: MIT Press.

WARNER, R. (1986): A Challenge to Physicalism. Australasian Journal of Philosophy, 64 (September): $249-265$.

Tufan Kiymaz

Bilkent University

Department of Philosophy, H249,

06800 Bilkent, Ankara

Turkey

e-mail: tufankiymaz@gmail.com

ORCID ID: 0000-0002-6631-3857 